\title{
Patent News
}

\section{THE DISTRIBUTION OF INVENTION IN ELECTRONICS}

Once again shortly after the publication of the final set of U.K. Patents for 1977 on December 28th last year Patintel were able to summarise the numbers of patents published in each of the seventy sections which are used in their classification system covering the whole field of electronics, instruments, control and associated technologies. Many interesting features emerge from a perusal of the table below which provides the numbers in all of the sections for each of the last three years. The most outstanding characteristic, however, continues to be the remarkable similarity of the numbers of patents published in the various sections in each year. One would, of course, expect some consistency as some of the subject sectors are of much greater importance in advancing technology than others. Nevertheless even the most ardent supporter of human consistency and those with the greatest faith in the regularity of such statistics can hardly fail to be impressed by the close similarity of some of the figures which emerge.

It can be seen in the section on "Film Circuits" where there is virtually no likelihood in classifying the invention, the 60 specifications published in 1977 compare with 62 in 1976. This quite remarkably consistent rate of invention is almost equalled in the case of monolithic Integrated Circuits with 134 in 1977 and 144 in the previous year, (with an equally impressive consistency in the higher rate of invention for discrete Semiconductor Devices). Optoelectronics also indicate a high and consistent rate of activity with 250 in 1977 as against 265 in 1976 and Lasers achieve similar consistency with 140 last year and 148 in the previous twelve months.

Not only is the annual "rate of innovation" consistent with the high technology sectors, for the Energy Conversion section, which relates mainly to batteries and storage cells, includes 288 specifications as against 285 previously.

For the convenience of some of their clients, Patintel have increased the number of classified sections (e.g. by opening up "Passive Components" to a wider range of seven sectors ranging from Connectors to Packages) and introducing a section on fibre optics. The general and surprising level of consistency does of course provide encouraging support for the claims made in regard to the achievement of consistent and reliable classification and readers might be interested to receive the weekly bulletin which summarises patents in all of these sectors and provides the patent number as well as the name of the patentee. This valuable publication is produced within one week of the publication of the specifications by the Patent Office and further information is available from Patintel, 13 North Avenue, Gosforth, Newcastle upon Tyne NE3 4DT

Total number of U.K. patents published annually in each of the subject categories used in Patintel's weekly alerting bulletin

$\begin{array}{rrr}1977 & 1976 & 1975 \\ 1 & 0 & 2 \\ 455 & 384 & 358 \\ 0 & 0 & 6 \\ 10 & 4 & 3 \\ 0 & 4 & 2 \\ 0 & 0 & 1 \\ 0 & 0 & 1 \\ 51 & 42 & 44 \\ 41 & 53 & 52 \\ 169 & 150 & 161 \\ 133 & 106 & 125 \\ & & \\ 250 & 274 & 168 \\ & & \\ 171 & 210 & 220 \\ 36 & 46 & 53 \\ 29 & 17 & 27 \\ 17 & 9 & 2 \\ 187 & 245 & \\ 145 & 242 & \\ 60 & 62 & \\ 91 & 124 & 726 \\ 297 & 242 & \\ 59 & 53 & \\ 26 & 18 & \\ 70 & 39 & 24 \\ 339 & 317 & 323 \\ 134 & 144 & 155\end{array}$




\begin{tabular}{|c|c|c|c|}
\hline & 1977 & 1976 & 1975 \\
\hline Superconductors \& Cryogenics & 29 & 61 & 48 \\
\hline Dielectrics, Insulators, Capacitors & 406 & 384 & 136 \\
\hline Magnetic Materials, Devices \& Equipment & 199 & 316 & 197 \\
\hline \multicolumn{4}{|l|}{ Vacuum Tubes, Gas Discharge, Display } \\
\hline Tubes CRT's and Spark Gaps & 214 & 263 & 286 \\
\hline $\begin{array}{l}\text { Optoelectronics, Photoelectric, LED's, } \\
\text { LCD's and I.R. Devices }\end{array}$ & 250 & 265 & \\
\hline Masers, Lasers and Holography & 140 & 148 & 136 \\
\hline Acousto- \& Magneto-electric Devices & 41 & 38 & 83 \\
\hline Ultrasonics, Sonics \& Piezo Devices & 105 & 132 & 54 \\
\hline \multicolumn{4}{|l|}{ Radiation, Electron Beam, Particles \& } \\
\hline Nucleonics & 209 & 220 & 180 \\
\hline Aerospace \& Military Electronics & 64 & 58 & 29 \\
\hline Sonar and Underwater Electronics & 24 & 23 & 18 \\
\hline Geophysical Measurements \& Equipment & 52 & 49 & 23 \\
\hline \multicolumn{4}{|l|}{ Medical Electronics \& Biomedical } \\
\hline Engineering & 150 & 174 & 125 \\
\hline Microwave Equipment & 111 & 90 & 72 \\
\hline \multirow{2}{*}{\multicolumn{4}{|c|}{$\begin{array}{l}\text { Cables, Transmission Lines, Waveguides, } \\
\text { Antennas }\end{array}$}} \\
\hline & & & 251 \\
\hline Fibre Optics and Optical Waveguides & 149\} & $-\}$ & - \\
\hline Communication Theory & 0 & 0 & 1 \\
\hline Telecommu & 328 & 340 & 358 \\
\hline Radar \& Navigation Systems & 129 & 149 & 138 \\
\hline \multicolumn{4}{|l|}{ Radio \& Television, Radio Paging \& } \\
\hline Intercom & 445 & 426 & 353 \\
\hline Audio Equipment & 262 & 216 & 143 \\
\hline Musical Equipment & 39 & 28 & 28 \\
\hline Horology & 138 & 130 & 99 \\
\hline \multicolumn{4}{|l|}{ General Domestic Equipment, Toys \& } \\
\hline Games & 178 & 150 & 58 \\
\hline Measurement Theory \& Standards & 0 & 0 & \\
\hline Measurement Instruments \& Techniques & 385 & 398 & 232 \\
\hline Transducers, Sensors \& Encoders & 262 & 160 & 153 \\
\hline Alarm Systems & 102 & 108 & 74 \\
\hline Control \& System Theory & 1 & 0 & \\
\hline \multicolumn{4}{|l|}{ Control \& Measurement of Particular } \\
\hline Parameters & 346 & 388 & 209 \\
\hline \multicolumn{4}{|l|}{ General Control Technology, Numerical } \\
\hline Control & 187 & 196 & 196 \\
\hline \multicolumn{4}{|l|}{ Electrical Power Networks, Lines, Cables, } \\
\hline H.V. Systems & 248 & 280 & 20 \\
\hline Power Stations & 1 & 2 & \\
\hline \multicolumn{4}{|l|}{ Power Equipment, Machines \& Circuit } \\
\hline Breakers & 339 & 327 & 132 \\
\hline Conversion \& Storage & 288 & 285 & 291 \\
\hline General Uses of Power & 0 & 0 & 7 \\
\hline \multicolumn{4}{|l|}{ Applications of Electronics and Power } \\
\hline & 462 & 317 & 83 \\
\hline Photography \& Printing Equipment & 750 & 776 & 497 \\
\hline Lamps \& Lighting Systems & 169 & 181 & 134 \\
\hline Automobile Electronics & 598 & 567 & 454 \\
\hline Rail, Air \& Sea Transport Sys & 106 & 111 & 100 \\
\hline General Applications of Electronics & 37 & 30 & 56 \\
\hline TOTAL & $\overline{8,830}$ & 0,745 & 8,144 \\
\hline
\end{tabular}

Note the remarkable similarity in the "rate of invention" in consecutive years in many of the subject categories which together cover all essential topics throughout the whole field of electronics, instruments, control and associated technologies. 

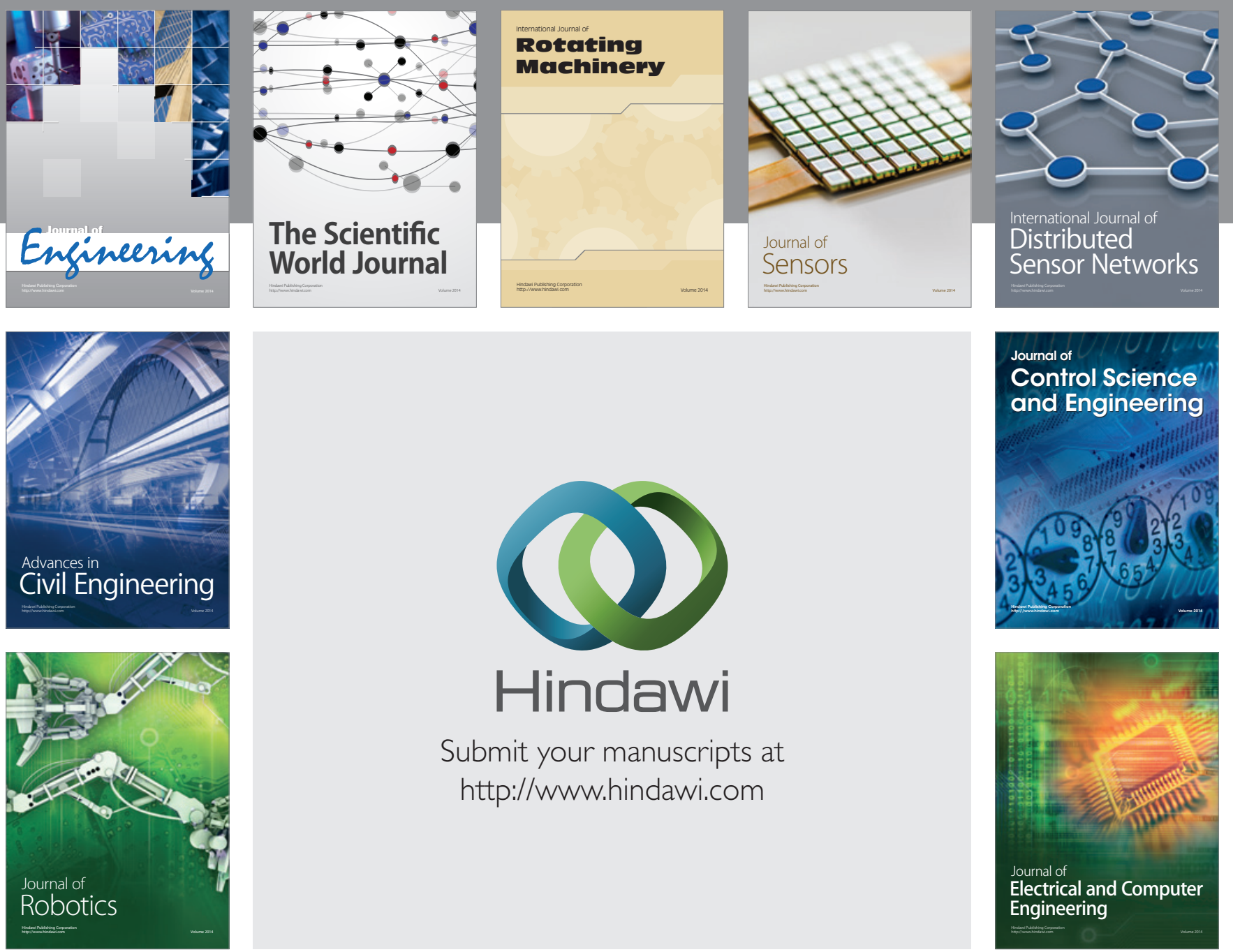

Submit your manuscripts at

http://www.hindawi.com
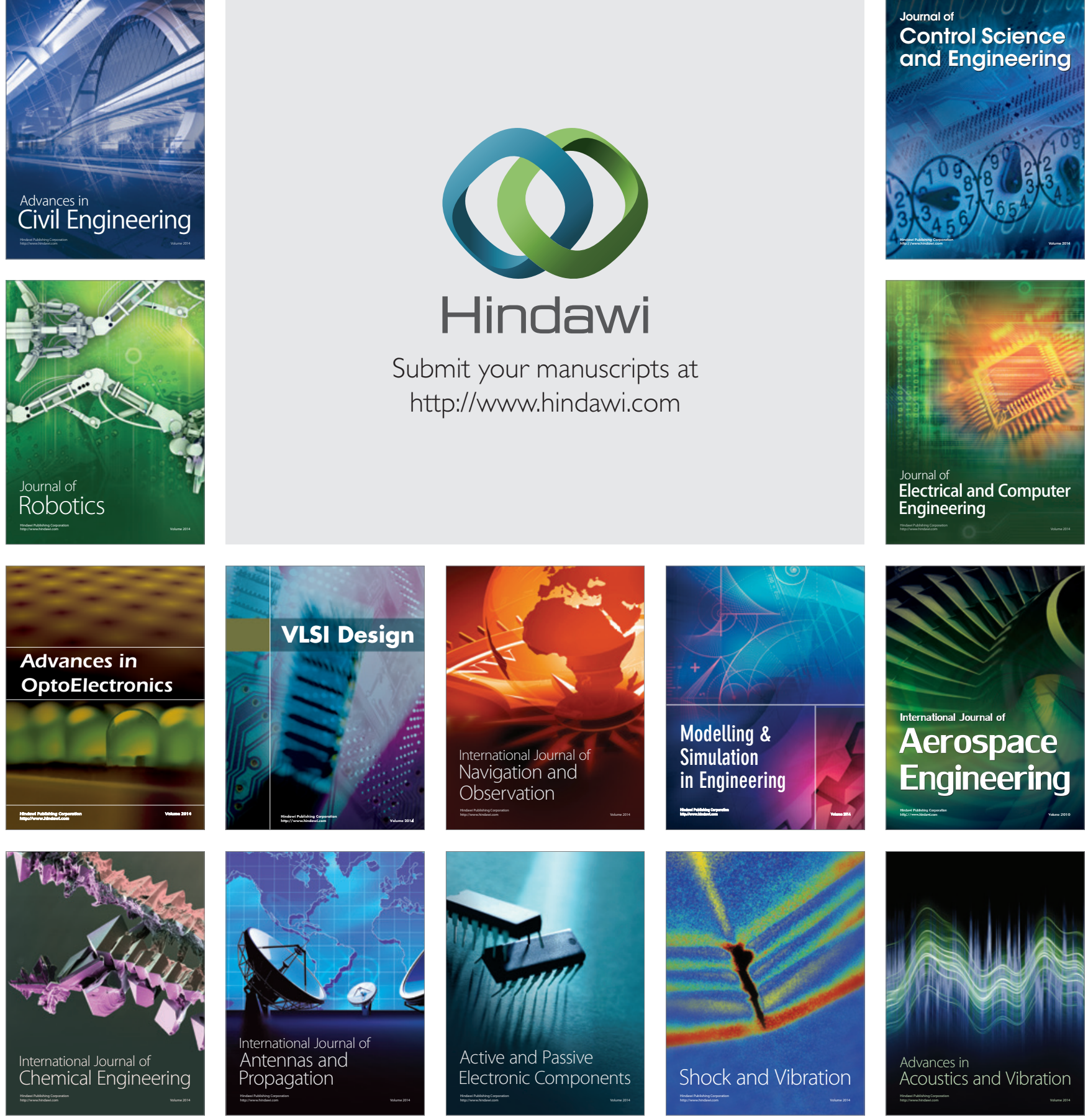